
A N A D D R R S S

\section{PROGRESS OF KNOWLEDGE IN THE} PHYSIOLOGY AND PATHOLOGY OF THE NERVOUS SYSTEM.

Delivered at the First Meeting of the Session of the Royal Medical and Chirurgical Society.

BY DAVID FERRIER, M.D., F.R.C.P., F.R.S., Professor of Forensic Medicine in King's College, and Physician to King's College Hospital.

Mr. Pregident and Fellows of the Roxal Medical and ChinURGICAL SOCIETY,-I have, in the first place, to express to you my very grateful appreciation of the great honour you have done me in awarding me the.Marshall Hall Prize this year, and in the further high privilege you have accorded me in asking me to address you on this occasion. To be the recipient of a prize associated with the name of Marshall Hall, and for work done in that department of medical science which he himself so adorned and enriched, is a distinction of which I am indeed proud. I know no name in the ranks of scientific medical inquiry, in this or any other country, which stands higher than that of Marshall Hall, and no work which has done more to advance physiology and pathology of the nervous system, and not this only, but medicine and surgery in general, than his in. vestigations into the nature and conditions of reflex action. This he was undoubtedly the first to formulate and expound, and clear from the vagueness and confusion which prevailed before him. The importance of his researches can scarcely be overestimated. If it were possible to eliminate from modern medicine all that relates to reflex action, its bearings and applications, we should practically derationalise the better half of pathology and therapeatics. Few scientific inquirers have been more keen to perceive the practical bearing of their own researches than Marshall Hall himself; and most of the principles that guide us in the recognition and treatment of diseases and symptoms dependent on reflex irritation were first clearly laid down by him. Not long prior to the time when Marshall Hall was pursuing his investigations on the spinal cord and medulla oblongata, Flourens was engaged on his ever memorable researches on the physiology of the cerebral hemispheres; and Flourens, also, to whom he dedicated several of his memoirs, was almost the first to perceive and recognise the valne of the work done by Marshall Hall, which many of his own countrymen endeavoured vainly to detract from and depreciate. If, at the distance of fifty odd years, we compare the relative stability of the work done by these great men, that of Marshall Hall on the spinal cord, and that of Flourens on the cerebral hemispheres, we find that the doctrines ennnciated by Marshall Hall, modified, perhaps, as to detail, and further extended by the numerous researches of recent years, are in all essential points those which stili prevail, and show no signs of failing; while those of Flourens, which have also exercised an enormous influence on clinical medicine and pathologywhat shall we say of them? In the brief sketch which I purpose giving you on the present position and probable future of this question, I fear that, however much we may try to avoid it, I shall appear more in the character of an adrocate, than of an impartial judge. But I am fully conscious that I am before a highly critical audience, who will not allow any bias of mine to warp their own just judgment.

The views of Flourens are familiar to you all. They seem to the scientific world at once in accordance with the facts and experiments on animals, at least of the lower orders, and in harmony with the prevalent metaphysical conception as to the unity and the indivisibility of mind. Like the mind itself, said Flonrens, the organ of the mind is also one and indivisible, there being no differentiation of function, but each and every part possessed of the potentialities and capability of exercising every function pertaining to the whole. These doctrines speedily met with general acceptance among physiologists, but there were a few keen clinical observers-De Boyer, Andral, and others-who saw in the phenomena of cerebral disease facts which appeared wholly inexplicable, except on the hypothesis of a differentiation of function, such for in:- stance as the occurrence of limited paralyses in connection with limited lesions. But nnable, on the other hand, to account for the facts of experiment on animals on the principle of localisation, which the clinical data seemed to demand, they wisely suspended their judgment, neither denying the facts of experiment, nor doubting their clinical observations, believing that the apparent discrepancies between human pathology and experimental physiology would one day be cleared up and dispelled. This was eminently the attitude of my distinguished predecessor in the honourable position I now hold. Dr. Hughlings Jackson, neither contesting nor trammelled by the doctrines of the school of physiology, saw, in the occurrence of a limited unilateral muscular spasm, in connection with certain cortical lesions, phenomena which, to him, signified irritation or discharge of grey matter directly related to mnscrlar movement; and with a keen prophetical insight, which far outran the slow march of verified fact, he evolved many brilliant and fruitful conceptions, as the anatomical substrata of the organ of the mind. There were, however, many other clinical facts, particnlarly those relating to the loss of speech in connection with lesions of the left hemisphere, which formed the subject of much lively debate and discussion twenty years ago, which remain equally obscure and mysterious, whether on the hypothesis of localisation or the reverse. It is not going too far to affirm that, np to the time when the researches of Fritsch and Hitzig inaugurated a new era in cerebral physiology, general doubt and confusion prevailed. It would even now be premature to claim that all this has been dispelled; but we may truly say that the questions in dispute have assumed a definite and manageable shape, and that every day the dark atmosphere is being cleared. I will not weary you with the keen controversies which arose as the true significanceand interpretation of the results which followed application of electrical irritation to different regions of the cerebral hemispheres. On these, as well as on the consequences of destructive lesions of the cortex, the most divergent views continued to be entertained and expressed. The fundamental question of localisation or no localisation was brought to a crisis at the meeting of the International Congress here in 1881. You are all aware, many of you doubtless heard and saw, that Professor Goltz, the chief of the few remaining champions of the Flourensian system, brought with him from strasburg a dog in which he had loag previously, at intervals, destrojed a large extent of the cortex of both hemispheres, and which he exhibited before the physiological world as a practical refutation of the theory of cerebral localisation. He enunciated the following thesis (I translate literally). "1. The cerebral cortex is the seat of the higher intellectual functions; the removal of large portions of both hemispheres degrades the intelligence. 2. It is impossible, by any localised cerebral lesion, to cause paralysis of any muscle; the animal operated on retains volitional control over all its muscles. 3. It is also impossible, by any localised certical lesion, to cause permanent loss of any sense. The animal retains all its sensory faculties. After removal, however, of large portions of the cortex, defective perception is cansed. 4 . Animals in which the parietal regions have been destroyed are permanently awkward in their movements, and defective as regards tactile sensibility. Animals in which the occipital lobes have been destroyed are, as a rule, more demented thas those in which only the parietal regions have been destroyed.' (International Medical Congress Report.) He pointed to his dog as an'illustration of the truth of these propositions : awkward in all its movements, especially those of the hind legs, but paralysed as to none; defective in all its faculties of sense and sensory perception, but neither blind nor deaf, nor otherwise totally deficient. Sone exceptions were taken by Professor Yeo and others as to the exact accuracy of Professor Goltz's description of the extent to which the motor and sensory faculties were impaired; but I pass over these as not essential to the matter in hand. When the brain of the dog was examined by a committee appointed by the Section, it was found that the lesions, though extensive in both hemispheres, were less than Professor Goltz had imagined, and did not implicate the whole either of the so-called motor region or of the region of special sense as defined by his opponents. Over against Professor Golts's dog were set two monkeys, in one of which the greater portion of the region called motor had been destroyed many months previously in the left hemisphere. The animal had remained he iplegic on the right side from the date of the operation, and at the date of the exhibition presented the typical features of hemiplegia, with late rigidity, as exhibited in man. The hemiplegia was seen and admitted by all, and the permanency of the result was sufficiently plain to all conversant with the inourable nature of hemipleyia
with late rigidity in human patients. It was afterwards proved bJ 
the committee of investigation, that the lesion in this case afiected only the cortical matter and subjacent medullary fibres in the region where it was said to be; and the fact of descending degeneration of the pyramidal tracts of the right side of the spinal cord was also establisherl at a later date. With the exception of the motor para. lysis of the right side, the animal was in all other respects perfectly well, full of intelligence, acute in its sensory facultics and powers of perception. The other animal, in which the superior teinporosphenoidal cinvolutions had some time previously been destroyed on both sides, presented a marked contrast to the first. There was no question as to this animal's motor powers; it bounded about and climbed hand over hand with the greatest agility and vivacity. Nor was there any question as to its sensory faculties, except one, namely, hearing; and in that respect it was almittel to be totally leficieni; for it was remarkerl by one present that it was the only animal in the room that was not startled by the explosion which I made. In this condition of total deafness, with retention of all its other faculties, both sensory and motor, it had been since the operation, and continued so till its death, a long period subsequently. The brain of this animal was exhilited at a meeting of the Physiologrical Society, and will be duscribed in another place. Suffice it to say that the lesions were confinerl to the cortical and subjacent merlullary fibres in the regions $I$ have indicated. It is at once oljvious that the second and third of the propositions enunciated by Professor fioltz (and it was admittel by himself) are demonstrably erroncous as applied to monkeys, and that, in their case, the localisation of function was incontestably proved.

To some, however, it appeared as though these demonstrations, instead of definitely scttling the question of cercbral localisation, had made confusion worse confounderl: a word or two, therefore, on the lessons taught on this occasion, and on the conclusions to which they logically lead. Localisation of function being admittedis rstablished in the case of one vertebrate animal, then, given facts and experiments on another animal of the same type seemingly at variance with this lnw, there is no alternative between either denying the universality of the law, or holding that the facts, though seemingly at variance, are, in reality, in perfect harmony with it. I cannot think it possible that, in the present state of biological science, any one will be found to maintain that animals constructed on the same anatumical type can differ so fundamentally in their physiological constitution as would be inplied in the first alternative. We must assume, therefore, that the whole question turns on how, on the principle of localisation, we are to account for such striking differences as are observable between the effects of clestruction of the cercural hemispheres in the rliferent orders of animals. It would be difficult, on a cursory exanination, to say whether a frog or a pigeon had had its ccrcobral hemispheres re: moved or not, if they earh maintainerl their normal attiture: the one will hr,p, and the other walk or fly, and rotherevise resprond to the sensory stimuli, in a manner little, if at all, different from the normal. The universal poworlessness, however, of even dogs. and inuch more so of tho higher vertebrates after a similar operation, will be very apparent. This fact, admitted by all, elearly demonstrates the existence of "rreat differences in degree amonir the different orders of animalis in ruspect to the part which the cereveral hemispheres play in the ordinary modes of activity and response to the various forms of external stimulation. If it is diflicult with some arimals to estimate t!e results of the rosnovial of the whole of thr: ecrebral hemisingeres, hrow much more roust it necesiarily brs to dretermine the effect of removing only a prortion. Neglect of the most isbvirous lessons of comparative physiology bas been the causs: of much uscless barren controversy farts being urged in oprosition to other fars s, between which no antisonisin really exists. If to these cronsillerations, founded in esroparative physiology, we ald that, unless the whole of a riven cortical co:ntre be destroyed, the function romining may suflice for the centinuation, in some degrce at least, of th" function allotted to it, we may arrive at a completely satisfaretrory explanation of the

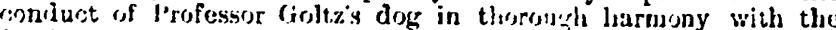
fundamerital principles of corobral localisiation.

I have purponcly excluded the elemente of elinical medicine in reference to this quest, for the exact solution of problems in physiology by fortuitous experiment on flisesss in man is al ways difficult, and nowhere more so than in t!e dornain of "arribial finction. The phenomena of cercbral rlisease are so comple: $z$, th; fuctors so inloterminate, that they seldom arlmit of exact analy is or corsputation; but, though all these clinioal oiservations snat be unable to carry riggid conclusions as to cause and (fïect, all phy hislogical generalisations otherwise foundeal must square with the facts of clinical observation before they can be admitted as integral parts of the institutes of medicine; and on many points, parti cularly when subjectivity is concerned, the observations on man constitute the only reliable means of interpretation of vital manifestation. Apart from some differences on matters of detail, which do not affect the main principle, localisation of curebral function is accepted by every recent writcr on cerebral disease as the only possible explanation of the phenomena. Mere numbers in authority, however, will not stanil for evidence. and I do not ruoste them as such: but, as it would be impossible for me to set forth the evidence here, I can only refer inquirers to what $I$ have elsewhere written on the subject, anil to the facts contained in the erore recent publications of Cliarest and l'itres, De Boser, (irasset, Nothnagel, Exner, Ross, and others, as well as to the cases, surh as those recently recorlecl by Dr. Sharpey, which are constantly apperaring in every merlical journal.

Assuming, therefore, that the principle of cerebral localisation has become established in physinlogy and clinical merlicine, the ground is cleared for the consideration of further questions of great scientific and practical importance, on which ofpinion is not unanimous, and on which, thercfore, further resenrch is de: sirable. The first is, is the localisation of centres a matter of indif ference or accident; or is it dependent on structural peculiaritic: and actions, which render each centre as distinct from others, as, for instance, one limb from another, or the organs of vision from the organs of hearing? Or, to put it in the form of a simile, is the brain-crust divided into fickls, each of which, though yickling some kind of produce, usually may, if need be, yicld any other? Or is it diviled into fields which siold only one kind of produce, and can yield no other? Or, according to still a third supposition, is it divided into ficlds cach of which yiells most of one kind of proluce, but more or less of every sort ? Each of these suppositions hats it. advocates and defenders. If the localisation be merely accidental or inclifferent, jerhaps the function of a part lesst may be taken on by some other of those remiaining; if it be structural, this would be as impossible as that the organ of hearing should perform the func. tions of the orgen of vision; or that the nervous apparatus which moves the leg sliould also move the tong:se, or act as the centre of taste. The question is one which ought to admit of definitive settle ment, by properly directed research. The indifferent theory hat: been adopted by many under the name of "functional compensation," as affording the most satisfactory explanation of the apparent recovery, after destruction of the cortical centres, of inotion in cer. tain of the lower animals. If it should appian, liswever, that in monkey's and still higher animals it is possible, by total extirpation of a given centre, to cause; complete and jermanent annililia. tion of a griven faculty of sense or motion, all others remaining intact, it is obvious that the hy pothesis of functional comprensation is uncalled for. Those who consirler this estathlisherl, cxplatin the apparent recovery in the lower animals on the: principles alrealy laid down respecting the differences in degrec in which the motor faculties and powers of response to the sensory stimuli are affected $b$ destruction of the cerctoral hemispheres in different orders of animals. The so-called "functional compensation" of the hemispheress is, in reality, no compensation at all, but only a manifestation of the activity of the lower centres. In andlition to the facts of experimental physiology demonstrating the possibility of entirely and permanently annihilating given functiony or faculty, others are adducisl in favour of a rigid structural locilisation. Though the grev matter of the cortex appears similar t!iroughout, and composed if clements common to every rerion more or less, yet recent histolosical researches, particularly those of Bevan J.ewis, have succcedul in determining the existence of numerons peculiaritios in structural arrangement and collocation in different rerrions of the cerestral cortex. The significance of thess structural peculiarities is by no means apparent; but that that they exist should have a meaning which may one rlay become elear, there is no room to doult. Perhaps is more intelligible signification than these histolo. gical incquiries lies in the facts now inclubitably establisher both by physiulogical exporiment and by human pathology, that wlien certain regions of the cortex, namely, thesse termed motor. are ire. stroyed, and no other seconrlary degeneration ensues in the pyra. vidal tracts, down the whols: leneth of the spinal corcl, this inferchec drawn from these clata is that, just is the; motor nerv:. are connecterl with the anterior horns of the spinal corrl, so thl. pyramidal tracts of the spinal cord are connected with certain $r$. gions of the cortex cerebri, showing therefore a fundamental differ.

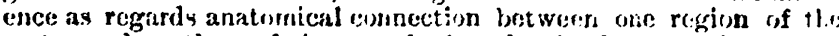
cortex and another. It is argued, also, that if the pyrituidal trac: had other connections, destruction of the? resions than the motos 
would induce secondary degeneration also, which is not the case, and that those connections, if they exist, should prevent the atrophy and degeneration which otherwise occur on destruction of the true motor area. As regards the region related to the organs of sense, it is stated as an established fact that the destruction of i certain cortical region on both sides causes complete and permancnt loos of vision, followed in due course by atrophy of the optic discs. This is relied on as proving that this region is anatomically the cercbral expansion of the optic tracts, and that the complete abolition of vision and subserjuent atrophy of the optic nerve show that this region is above the centre of vision, and that if the optic nerve have connection with any other region or regions, these are unable to form the substrata of the visual sense, or prevent the wasting of the optic nerve. No similar observations have as yet been marle on the atrophic relation, if any, between particular cortical areas and othor organs of special sense; some cases have, however, been published in favour of the occurrence of atrophy in certain cortical regions as the result of long-standing deprivation or congenital absence of some limb or organ of sense. Many of these, however, have an extremely slender foundation, and much is required, in the way of future research, before conclusions can be safely founded on them; but if succecting research should establish sucl, facts, free from doubt and uncertainty, and if all the statements should he substantiated in reference to the permanency of the effect of cortical lesions and the consecutive regeneration of certain tracts and organs, the question of inclifferent or rigid strnctural localisation will have been delinitely settled.

After the fundamental principle of localisation itself, whoever, all the other points involval in it, whatever may bo their scieutific: interest, sink in importance, as regarcls practical ends, in com. parison with those relating to the exact delimitation of the respective cortical centres. Here we meet with a consislcrable

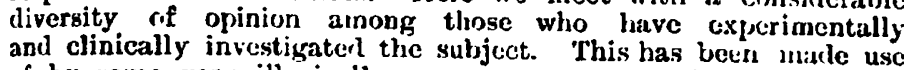
of by some, very illogically, as an argument against localisation altogether. It migit be alleged, with as much reason, that any lifference of opinion among llue Fellows of this Socicty on ques. tions brought before them, are a sign of instability on the part of the society itself. I should require a treatise ratber then the limits of a brief sketch to plines: before you the various facts and argu. ments on cach hearl, and I should have to import many thing's of my own as yet unpublisherl, for which this is neither the tiune nor the place. I content mysclf, therefore, with morely indicating points on which there is more or less harmony, or the reverse. The convo. litions bounding the fissure of Rolando are, without exception, re. garded as having a special relation to the motor powers. Whetlice motor disorders are invariably caused by lesions in this region, is a point of capital importance. If clinical rescarch should establish the existence of an uncxceptionable casc of total destruction of this so-called motor rerrion without motor paralysis, such a case will di, more towards demolishing the whole theory of the cxistrence of motor centres in the huinan brain than any hunitrels and thousands of cases arlduced in support of it. But, naturally, the positive clinical instances and the established data of exporimential physiology, we have a right to rlemanil something incre than mere vague assertion or crude investigation before a negative instance can be admitterl as proved. None such has as yet becn put on record; all the doubtful cascs, cxtremely few in nusnber, bear only on the precise limits of the respective centres, and not on the general question of the existence or not of a special motor area. The centres of hearing have been shown before the plyssiological work to be in the superior temporo-sphenoidal convelution; ind numerous clinical observations have been put on recort favouring the existence of a causal relationship between the lesions of this region in the left hemisphere and the occurrence of the defect termed word-deafness a defect in the representative functions of the auditory contre. Nothing, however, comparable to tlie absolute deafness, presentative as well as representative, seen in the monkey from bilateral destruction of this reigion, lius us yet been ob.c.rverl in man.

The centres of vision are still the subject of some differences of opinion; but these differences have reference not so much to tho general position as to the exact delinitation of the anterior boundary, and to the relations of each centre to the central and peripheral portions of the retina respoctively. Clinical observations are being published in considerable numbers demonstrating the occurrence of isolated affection of vision in connection with cortical and subcortical lesions in the occipito-angular regions, ind the difierences between the published vicws on the relation of the centres of the organs of vision are in proccss of being settled.

The centres of smull and taste are less definitely determined. conces of all obtain in reference to the localisation of the centres of common and muscular sensibility. A considerable number of physiologists place them in the so-called motor region, while: I have all along held, and hold, both on experimental and clinical grounds, tomically centres of common, inclurling muscular, sensibility, are anstomically cntirely distinct from those of motion, and situated in question should region. It is of the utmost inportance that this question should be settled, for it involves vital issucs in the region lesions. In this respect. clinical of cortical from other cerebral work, has a transcendent value, and there is ciary reason to believe that this, in combination with a more precise experimentisl method, will at no distant date succecd in solving outstanding difliculties, securing a gencral harmony of opinion, and placing cerclural locialisation and the regional diagnosis of cerebral discase on $a$ frm and unas. sailable foundation. In no department of merlical science is more activity being manifester, and there is no field more inviting, os more likely to repay cultivation. The following words of Mar.shall IIall are perhaps more pertinent now than they were in his own time: "In every point of view there is much to be done. in livery onncouragement should be given to the diligent, devoterl investigfator; every obstacle, every kind of injustice, every source of clisgust and indignation ought, for the sake of science and for the honour of our institutions, to be rernoved. The physician who devotes himself to investigation makes a thousand sacrifices; his faith reruires cheering, and should not, need not, be unjustly obstructed or beset with thorns. Though the value of scientific investigation is by no means fuct or principle is enlianced in the eyes of all mankind if it be useful as well as true." Testerl by the stanclard of practical utility, what, it is asked, has ccrebral localisation done, or is it discase than we can yet boast of ? lip to the present, I think that, with a few though insignificant cxceptions, the benelits of the scientific doctrine of cerebral locialisation have been absorbed, like so much latent heat, by medical science itself, as distinct from medical or surgical practice. It has been as a lamp to lighten the path of the clinicist through a darkness almost. chavtic; it has sharpened clinical vision, so that now many things: are clearly seen which were formerly supposerl not to exist: it has given a decision to clinical and patloological rlescriptions which will be scarched for in vain in the older recurds; it has cleared our conception as to the significance of numcrous symptoms, and rationalised many purely empirical generalisations, and is every day modern medieine, namely, locealisation of has termed the goal of modern medicine, namely, localisation of discase. But when this determine the nature and position of the discase, when we are able to that we shall stop liere? 'This would be very inprobable, even though we should as yet have none or only the most vague notion. in wlat direction practice may tee influenced. But there are already signs that we are within measurable distance of the successful hopeless forms of intracranial discase, which will vie with the achicvements of abdominal surgery.

It is natural that physicians should hesitate to advise surgical operations on the brain, and that surgeons should stay their hands until the principles and diagnosis of regionnl disease had been esall is hidden from the cye and hand. But, granting this, is there any reason why a surgeon should shrink from opening the cranial
cavity, who fearlessly exposes abdominal viscera? The peritoneum was, until a recent date, held sacred anil inviolable. The dura mater and the brain are much in the same position now. But, after what I have seen of the unfailing safety, the freedom from all un. towarl results as regards health and life, with which the most forniilable and repeated operations can be performed on the brain ani animals of the most delicate, almost human organisation, I cannot
but believe that similar results are capable of being achicved or but believe
man himself.

Apart from secondary infiarnmation and its conscquoncey, which can be absolintely preverted, there is no risk to life from even extensive destruction of the ccrebral hemispheres. It is true that, in attempts to remove tumours, or locially treat other forms of 
disease, we may injure or destroy healthy portions of the braintissue. But what will follow? Not necessarily mental disorder or sppreciable mental defect.

With the exception of certain functions arrogated by the left homisphere, we have, for mental purposes, practically two brains; and diseases are not always on the left side. The records of our daily experience of disease and injury of the brain show that considerable portions of the brain-substance may be destroyed without great danger to mental stability. But paralysis may ensue, more or less extensive, or defects in special sense, according to the position and amount of lesion. Such risk undoubtedly exists, as well as athers incident to the operation itself, as to all surgical operations. But the choice is not between this and any other mode of treatment, but between running these risks and certain death; and $I$ have no doubt that there are many who, if they had the choice, would rather go through, if not enjoy, life, halt or hemiopic, than perish miserably after sears, it may be, of incessant suffering. "Ne sutor ultra crepidam," I think I hear some one say. I applaud the sentiment; but as in this matter I have had the experience of the surgeon, as well as the physiologist and the physician, I have thought that I might venture on these suggestions without appearing to go very far beyond my last.

OLEaTe of QUINIA.-Dr. Squibb, in his Ephemeris, consfders that oleate of quinia, although it has not attracted general attention, is probably one of the most important of the oleates. From the larger quantity of quinia needed in medicine, this oleate is made as strong as possible. While a normal oleate of this alkaloid would by calculation contain about 53 per cent. of the alkaloid, it has been found impracticable to dissolve that quantity in the acid. In a series of experiments made some years ago, when this oleate was introduced, it was concluded that 25 per cent. was the best proportion. But as the quinia of the market holds' some hygrometric moisture, it is better to take 26 grains of the alkaloid and 74 grains of oleic acid as the formula. The alkaloid is simply rubbed to powder, and added to the acid in $\dot{a}$ bottle. Like the other alkaloids, this dissolves so readily that, being in much larger proportion, it is liable to clog together and be slow in dissolving. But this clogging together is easily broken up by means of a glass rod, or the solution may be effected in a capsule, and the clogging be prevented by a pestle. In this way it is easily made in a few minutes. A fluid ounce of this oleate weighs about 410 grains, and, therefore, contains about 102 grains of quinia, which is equivalent to about 140 grains of the ordinary sulphate of quinia ; therefore, a fluid drachm contains the equivalent of about 17 grains of the sulphate and 2 minim is equivalent to a little more than a quarter of a grain. An hypodermic injection of a fluid drachm will, therefore, carry the equiralent of 17 to 18 grains of sulphate of quinia. It happens, perhaps, oftener with the administration of quinia than most other medicines, that the physician wants to save the stomach; and many conditions need quinia when the stomach will not accept it, or wil not utilise it if given by the mouth. These circumstances have long indicated the hypodermic use of quinia, but up to this time no solution has been proposed that is well adapted to hypodermic use, first. because of the large dose required, and again, because of sparing solubility of available quinia salts. Hence this oleate has been sometimes used hypodermically, bat with what success is unknown to the writer. The epidermic use, however, is of late not uncommon, and, since it was first proposed, occasional trustworthy testimony from private sources has led the writer to consider it an importantadjunct to the more common methods of using quinia. "The quantity of oleate needed here is considerable, often amounting to one or two fluid drachms. Hence it should always be applied under oiled silk or gutta-percha tissue. When put directly on the șkin; a minim will require about four square inches of surface or it will run, and a fluid drachm would require about two square feet of surface; an area hardly accessible under ordinary circumstances. But two pieces of very thin fine old muslin or linen, six by nine inches, will easily hold half a fluid drachm each, and may be applied to the inside of the thighs, covered by oiled silk. This leaves the abdomen available for another similar application if desirable, and the oleate can be renewed on these places as rapidly as it is absorbed. Another good way of applying it, especially in walking cases, to get a moderate continuous effect, is to anoint the spinal tract for an inch or more on each side of the spinous processes, morning and evening, with a half fluid drachm, and cover it with a strip of oifed silk under the clothing. The writer has heard of several instanees in thich a ringing in the ears was speedily produced by such applications of the oleate.

\section{INTRODUCTORY LECTURE}

\section{ON THE PROVINCE OF ANATOMY.}

BY ALEXANDER MACALISTER, M.D., F.R.S.,

Fellow of St. John's College, and Professor of Anatomy in the University of Cambridge.

ThIRTY years ago it would have been unnecessary, even for a new professor in a new place, to commence his lecture on anatomy by defining, in a somewhat apologetic strain, the position, in the medical curriculum, of the science which it is his province to teach. No one then questioned that upon a carefully taught anatomy as a foundation all sound medical teaching should be based.

Within the last few years, many changes have taken place; the range of medical study has widened, new subjects have been im. ported, and new branches of older subjects have largely developed; while the student is expected to master this increased curriculum in the same period as that which was formerly thought necessary for a much more limited course.

The consequences of these changes are obvious. Many of the new subjects, from their very novelty, from the attractiveness of their method, the skill of their teachers, as well as their intrinsic importance, now claim a large share of the student's attention; and to provide the time necessary for their study, there is a growing tendency to curtail that spent in the pursuit of other subjects, each teacher setting forth his own science as that of primary importance.

In this conflict of opinion, the relative positions of the sciences fundamental to the medical oourse is liable to be misunderstood; the older and less attractive falling into a position inferior to that which they really deserve, while at the same time the diversity of the student's occupation tends to encourage superficiality rather than thorough knowledge, so that the man who passes through the extended course in the prescribed time can rarely do more than absorb a smattering of each science.

The real solution of this difficalty, and that to which experience is fast bringing us, is the lengthening of the curriculum, so that in the additional year the balance of subjects of study can be more carefully adjusted with a due regard to their relative importance.

But we have not met together here and now to legislate as to the future arrangements of medical study, but to consider what position anatomy should occupy in your own system of studies, and how much of your time and attention you ought to give to it.

By your presence here, I assume that most of you intend to devote Jour lives to the study and practice of medicine or surgery. A few of you may be parsuing the subject for its own sake; some, $I$ hope, with the prospect of being the scientific teachers of the future; but, judging from the history of Cambridge graduates in the past, $I$ conclude that, even in this most favoured of schools, most of you wish for a kind of knowledge which you can turn to practical account; useful not merely for the intermediate ordeal of your examination, but also for your after-life of practice. If this be so, it is surely of foremost importance that you should have as perfect a knowledge as possible of the human body in health, and it is this knowledge which constitutes anatomy.

I wish you to bear in mind that anatomy is an exceedingly wide subject, one which requires to be viewed in two aspects, as an art and as a science. The art of the anatomist deals with the examination of the structure of the haman body, not only of its coarser larger arrangements, recognisable by the naked eye, and separable by the knife and forceps, but also of the finer building up of the textures, the minute organisation revealed by the microscope, seen in sections, developed by reagents - in short, with the unfolding of the physical characters and relations of the component parts of the human body, including all that we now call histology, which is but one small subdivision of anatomy.

But the science of anatomy is much wider than the art. Every tissue and every organ in the body has had a history, which it is the business of the anatomist to search out and record. At some period in the life of the individual, it has begun to be, and, through many vicissitudes of time and circumstance, has attained to its adult condition. This branch of our science we call embryology ; but it is simply the historical side of anatomy, essential to and inseparable from the rest of the science, to which we shall hate frequent occa- 